\title{
Peningkatan Pengetahuan tentang Senam Desminorea untuk Mengurangi Nyeri pada Siswa SMA di Kota Denpasar
}

\author{
Ni Komang Tri Agustini ${ }^{1}$, Ida Ayu Ningrat Pangruating Diyu ${ }^{2}$ \\ 1,2 Institut Teknologi dan Kesehatan Bali
}

\begin{abstract}
Article History ABSTRACT
Received 19.08.2019

Received in revised form

23.11.2019

Accepted 02.12.2019

Available online 16.12.2019

INCREASED KNOWLEDGE ABOUT DESMINOREA GYMNASTICS TO REDUCE PAIN IN HIGH SCHOOL STUDENTS IN DENPASAR CITY. Menstrual pain or dysmenorrheal is a physical disorder that is often felt by women every menstruation. Dysmenorrheal is often reported to interfere with daily activities. The incidence of dysmenorrheal shows that the experience of dysmenorrheal is mostly experienced by adolescents, including adolescent in high school. To reduce the menstrual pain every menstruation requires sufficient knowledge and understanding of the actions that can be done to reduce menstrual pain, one of them is dysmenorrheal exercises. This activity aims to provide education about dysmenorrheal exercises used to reduce menstrual pain. The method used is to provide health education about menstrual pain and training about dysmenorrheal exercise. Before and after counseling pre test and post test. The results of counseling showed an increase in teenagers understanding of dysmenorrheal exercise to reduce menstrual pain, from $52.5 \%$ to $80 \%$. Based on these results it is expected that teenagers are able to practice dysmenorrheal exercises to reduce menstrual pain.
\end{abstract}

KEYWORDS: Dysmenorrheal Exercise, Menstrual Pain, Teenagers.

\section{PENDAHULUAN}

Remaja pada umumnya mengalami pubertas yaitu tahap transisi dari masa kanakkanak menuju kematangan seksual. Terjadinya percepatan pertumbuhan, pematangan tulang rangka, perkembangan karakteristik seksual dan pencapaian fertilitas. Menarke (onset menstruasi) biasanya terjadi 2-3 tahun setelah telarke (perkembangan payudara) pada usia rata-rata 11-13 tahun. Siklus di awal seringkali bersifat anovulatoris dan tidak teratur. (Isnaei \& Kusmiati, 2016).

\footnotetext{
${ }^{1}$ Corresponding author: Institut Teknologi dan Kesehatan Bali. Jl. Tukad Balian No.180, Renon, Kec. Denpasar Sel., Kota Denpasar, Bal 80227, Indonesia. Email: agustini.komang90@gmail.com
} 
Pada siklus menstruasi beberapa wanita mengalami disminorea. Dismenorea didefinisikan sebagai nyeri uterus yang bersifat siklik yang terjadi sebelum atau selama menstruasi. Dismenorea primer tidak berhubungan dengan patologi panggul dan dianggap sebagai akibat produksi prostaglandin yang berlebihan oleh uterus sedangkan dismenorea sekunder biasanya disebabkan oleh kondisi-kondisi yang didapat seperti endometriosis (Bobak, Lowdermilk, Jensen, \& Perry, 2005).

Dismenorea adalah gangguan fisik pada wanita yang sedang menstruasi berupa gangguan nyeri/ kram perut. Kram tersebut terutama dirasakan di daerah perut bagian bawah menjalar ke punggung atau permukaan dalam paha. Sebesar $64,25 \%$ wanita di Indonesia melaporkan kejadian dismnorea yang terdiri dari 54,89\% dismenorea primer dan 9,36\% dismenorea sekunder (Proverawati \& Misaroh, 2009). Berdasarkan penelitian Mahmudiono (2011), angka kejadian disminorea primer mencapai 53,89\% pada remaja dengan rentang usia 14-19 tahun. Berdasarkan hal tersebut menunjukkan bahwa pengalaman disminorea dialami oleh anak usia remaja termasuk didalamnya anak yang duduk di bangku menengah atas (SMA).

Latihan-latihan olahraga yang ringan seperti senam sangat dianjurkan untuk mengurangi dismenore. Pencegahan yang dapat dilakukan dengan cara melakukan senam atau disebut dengan senam dismenore (Puji, 2009; Marlinda \& Purwaningsih, 2013). Senam merupakan salah satu teknik relaksasi yang dapat digunakan untuk mengurangi nyeri karena saat melakukan senam, otak dan susunan saraf tulang belakang akan menghasilkan endorphin, hormon yang berfungsi sebagai obat penenang alami dan menimbulkan rasa nyaman (Marlinda \& Purwaningsih, 2013).

Hasil penelitian yang dilakukan oleh Hesti Lestari (2009) menunjukkan meskipun disminorea merupakan masalah, $82 \%$ remaja memilih untuk membiarkan saja nyeri yang timbul atau mengatasinya dengan cara tradisional yaitu minum air hangat atau menekan bagian yang sakit dengan kompres hangat. Hal ini dapat menjadi indikasi perlunya pendidikan kesehatan serta simulasi senam disminore untuk mengatasi disminorea bagi remaja putri.

Angka kejadian desminoreadi Indonesia adalah 55\% di kalangan usia produktif, 15\% diantaranya mengeluhkan keterbatasan aktivitas akibat dismenorea (Fahmi, 2014). Angka kejadian desminore belum ada laporan secara resmi, namun terdapat beberapa penelitan yang memamparkan angka kejadian dismenorea di Bali bahwa remaja yang mengalami dismenore dengan skala nyeri sedang sebanyak $55,6 \%$, skala nyeri ringan $14,8 \%$ dan skala nyeri berat 29,6\% (Iswari, Surinati, \& Mastini, 2014)

SMA 1 Saraswati Denpasar dipilih sebagai tempat penyelenggaraan kegiatan pengabdian masyarakat ini karena sekolah ini belum pernah mendapatkan sosialisasi tentang nyeri haid dan demonstrasi senam desminore di sekolah. Selain itu,berdasarkan informasi dari kepala sekolah dan Pembina KSPAN (KelompokSiswaPeduli AIDS danNarkoba), sekolah ini memiliki ekstra kurikuler KSPAN dan juga program konselor sebaya yang menyatakan banyak siswi sering mengalami nyeri haid dan perlu pendidikan kesehatan tentang nyeri haid dan cara menanggulanginya.

Berdasarkan permasalahan yang telah ditelusuri dengan tim, maka yang menjadi target adalah seluruh siswi remaja di SMA 1 Saraswati Denpasar. Kriteria yang menjadi target program pelaksanaan pengabdian masyarakat ini adalah pemaparan tentang nyeri 
haid dan penanggulangannya serta pengenalan kegiatan senam disminore pada siswa perempuan yang pernah mengalami nyeri haid (disminore).

Luaran program yang dihasilkan dalam program pengenalan senam disminore di lingkungan sekolah ini adalah penyuluhan kesehatan (manfaat senam disminore), poster dan leaflet gerakan senam disminore, artikel dan laporan kegiatan.

\section{METODE PELAKSANAAN}

Metode pelaksanaan kegiatan ini adalah melakukan identifikasi pengetahuan awal siswi mengenai nyeri haid (desminorea) selanjutnya pemberian edukasi kesehatan melalui pemberian materi tentang disminorea dan cara mengatasi disminorea, pemberian dan pelatihan/ simulasi tentang senam disminorea, evaluasi terhadap pemahaman siswa tentang disminorea serta manajemen disminorea melalui senam disminorea, dan penyediaan fasilitas yang mendukung seperti poster maupun leaflet.

Adapun mekanisme pelaksanaan kegiatan ini merujuk pada 4 langkah action research yaitu: perencanaan, tindakan, observasi dan evaluasi, serta refleksi. Pada tahap pertama adalah perencanaan, kegiatan yang dilakukan adalah mengurus perizinan ke sekolah yang bersangkutan, sosialisasi pelaksanaan kegiatan penyuluhan dengan pihak terkait seperti guru, OSIS dan perwakilan siswa dan menyusun program penyuluhan senam disminore. Selanjutnya pada tahap pelaksanaan, kegiatan yang dilakukan adalah pre test dan post test mengenai pengetahuan tentang disminorea, edukasi tentang disminore dan cara mengatasinya, mendemonstrasikan senam disminore, melakukan simulasi mandiri senam disminore dan menyediakan fasilitas poster dan leaflet senam disminore. Pada tahap ketiga dilakukan proses observasi implementasi kegiatan. Instrumen yang digunakan untuk observasi dan monitoring berupa pre test dan post test. Tahap terakhir adalah refleksi dilakukan terhadap kegiatan yang telah dilaksanakan. Hal ini dilakukan untuk mengetahui kekurangan-kekurangan atau kelebihan-kelebihan terhadap kegiatan yang telah dilakukan dalam rangka untuk menetapkan rekomendasi terhadap keberlangsungan atau pengembangan kegiatan berikutnya.

\section{HASIL DAN PEMBAHASAN}

Pelaksanaan kegiatan Pengabdian Kepada Masyarakat (PKM) dengan judul PKM Pemberian Pendidikan Kesehatan dan Simulasi Senam Disminorea Sebagai Upaya Mengurangi Kejadian Nyeri Haid (Desminore) pada Remaja Di SMA Saraswati 1 Denpasar berlangsung baik dan lancar. Kegiatan PKM dilaksanakan sebanyak 3 kali. Kunjungan pertama dilakukan pembagian kuesioner pengetahuan siswa tentang disminorea serta penyuluhan disminorea. Pertemuan kedua dilaksanakan dengan agenda simulasi senam disminorea. Pertemuan ketiga adalah evaluasi kegiatan dan pengisian kuesioner evaluasi.

Pendidikan Kesehatan tentang nyeri haid diberikan kepada siswi remaja kelas 10 di SMA Saraswati 1 Denpasar sebanyak 40 orang. Sebelum mendapat pendidikan kesehatan, siswi diberikan pre test untuk mengetahui tingkat pengetahuan siswi tentang nyeri haid dan sikap yang dilakukan sebagai tindakan penanganan nyeri haid. Kegiatan dalam pertemuan pertama ini dimulai pukul 09.00 WITA sampai dengan pukul 12.00 WITA 
dengan agenda kegiatan antara lain pembagian kuesioner pengetahuan siswa mengenai disminore serta penyuluhan disminore. Berdasarkan hasil analisis dari 40 siswa yang mengisi kuisioner, diperoleh 30 orang $(75 \%)$ mengalami disminorea setiap bulannya dan 10 orang (25\%) tidak mengalami disminorea setiap bulannya (Tabel 1).

Tabel 1. Kejadian Disminorea

\begin{tabular}{lcc}
\hline Variabel & F & $\%$ \\
\hline Mengalami desminorea & 30 & 75 \\
Tidak mengalami desminorea & 10 & 25 \\
\hline
\end{tabular}

Tabel 1 menunjukkan 30 orang (75\%) mengalami disminorea setiap bulannya dan 10 orang $(25 \%)$ tidak mengalami disminorea setiap bulannya

Tabel. 2. Kategori Pengetahuan Sebelum Diberikan Pendidikan Kesehatan

\begin{tabular}{lcc}
\hline Variabel & F & $\%$ \\
\hline Pengetahuan baik & 21 & 52,5 \\
Pengetahuan kurang & 19 & 47,5 \\
\hline
\end{tabular}

Tabel 2 menunjukkan sebanyak 21 orang (52,5\%) memiliki pengetahuan yang kurang dan sebanyak $19(47,5 \%)$ orang memiliki pemahaman yang baik.

Setelah selesai mengisi kuisioner pre test, dilanjutkan dengan pemberian materi pendidikan kesehatan tentang nyeri haid. Siswi tampak antusias dan mendengarkan penyuluh saat menjelaskan tentang nyeri haid dan tindakan penanganan yang perlu dilakukan. Siswi juga memberikan pertanyaan sekitar nyeri haid dan tindakan penanganan. Kegiatan kemudian dilanjutkan dengan pemberian penyuluhan mengenai nyeri haid /disminorea. Materi penyuluhan berisikan definisi menstruasi dan disminorea, tanda dan gejala disminorea, hal-hal yang dapat digunakan untuk meredakan disminorea. Pemberian pendidikan kesehatan ditutup dengan pemberian kuisioner post test untuk mengevaluasi tingkat pemahaman siswi tentang materi yang telah diberikan.

Dari hasil evaluasi post test menunjukkan sebanyak 32 orang $(80 \%)$ memilikipengetahuan yang baik dan sebanyak 8 orang $(20 \%)$ memiliki pengetahuan yang buruk (Tabel 3).

Tabel 3. Pengetahuan Siswa Setelah Diberikan Pendidikan Kesehatan

\begin{tabular}{lcc}
\hline Variabel & F & $\%$ \\
\hline Pengetahuan baik & 32 & 80 \\
Pengetahuan kurang & 8 & 20 \\
\hline
\end{tabular}

Tabel 3 menunjukkan sebanyak 32 orang ( $80 \%$ ) memiliki pengetahuan yang baik dan sebanyak 8 orang $(20 \%)$ memiliki pengetahuan yang buruk.

Kegiatan selanjutnya adalah simulasi/pelatihan yang diawali dengan demostrasi oleh tim kemudian dilanjutkan dengan simulasi oleh siswa. Hasil dari simulasi senamdesminore ini adalah peserta mampu mengulang kembali gerakan senam desminore yang telah diajarkan sesuai dengan langkah-langkah yang telah diberikan. Simulasi senam desminore ini diawali dengan mencontohkan gerakan senam desminore 
kemudian diikuti oleh seluruh peserta, selanjutnya peserta melakukan sendiri senam desminorea tanpa ada contoh. Cara yang dilakukan untuk mempermudah mengingat adalah dengan memberikan leaflet dan video yang berisi gerakan lengkap tentang senam desminore. Hasil yang didapat bahwa seluruh peserta mampu mengulang kembali gerakan yang telah diajarkan.

Kegiatan pengabdian masyarakat ini telah mampu mengevaluasi pengetahuan remaja tentang nyeri haid/disminorea dan meningkatkan pemahaman remaja tentang cara mengurangi nyeri haid. Remaja juga telah mampu mendemonstrasikan gerakan senam disminorea. Kelemahan dalam kegiatan pengabdian masyarakat ini adalah belum bias mengevaluasi secara berkelanjutan tentang efek dari senam desminorea dalam mengurangi nyeri haid/desminorea.

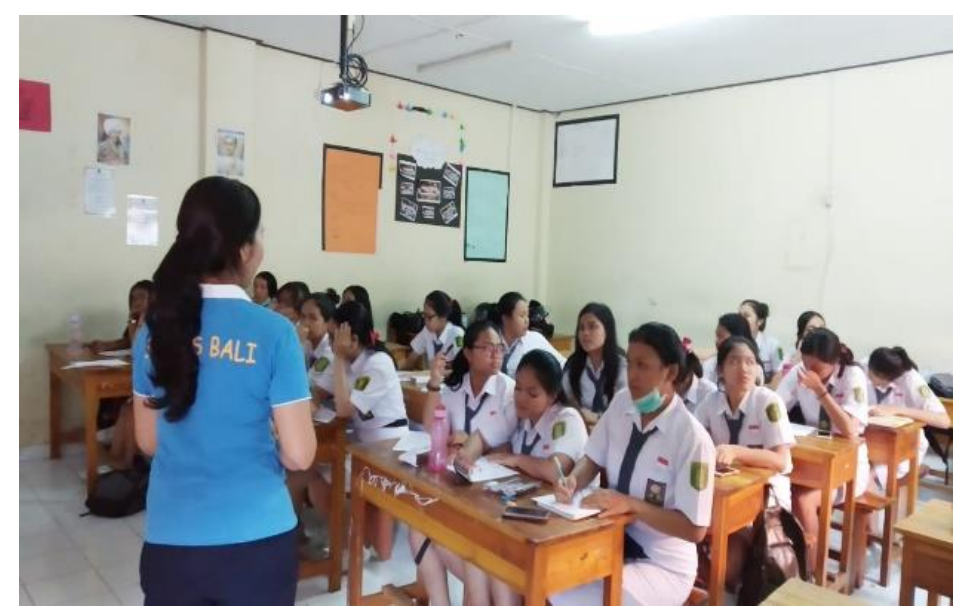

Gambar 1. Penyuluhan tentang Nyeri Haid

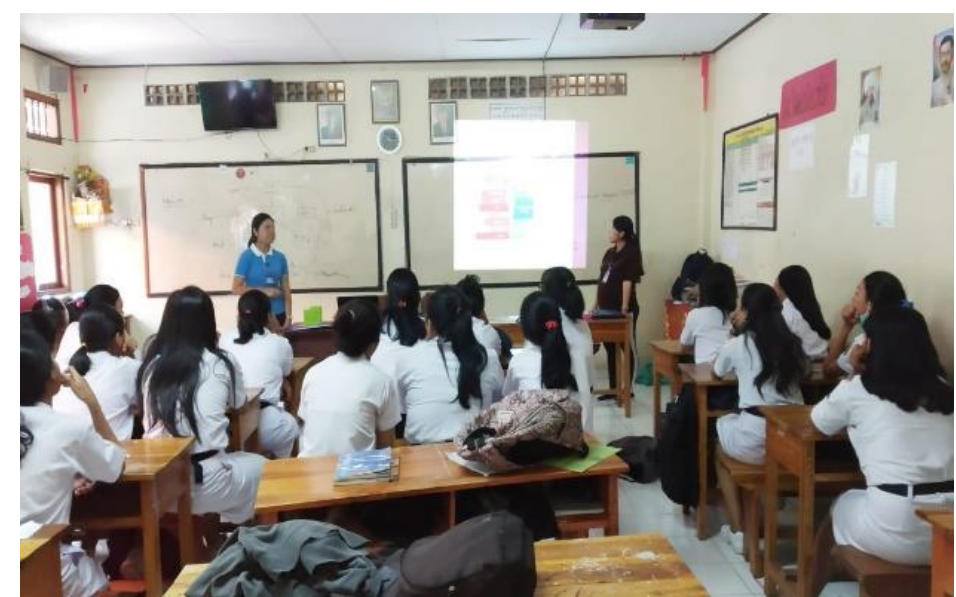

Gambar 2. Penyuluhan tentang Senam Desminore

\section{SIMPULAN}

Berdasarkan pemaparan seluruh kegiatan berupa pendidikan kesehatan tentang nyeri haid serta pemberian simulasi dan demonstrasi tentang senam desminore pada siswi remaja sebagai upaya untuk mengurangi kejadian nyeri haid dapat disimpulkan 
bahwa sejumlah target yang sudah tercapai diantaranya: 1) Peserta (siswi SMA Saraswati 1 Denpasar) mampu memahami materi pendidikan kesehatan tentang nyeri haid; 2) Terdapat peningkatan pengetahuan antara sebelum dan sesudah diberikan pendidikan kesehatan tentang nyeri haid, tindakan penanganan nyeri haid dan pelaksanaan senam desminore; dan 3) Peserta mampu melakukan senam desminore dengan baik sesuai dengan langkah-langkah yang berikan oleh tim penyuluh.

\section{REFERENSI}

Bobak, I. M., Lowdermilk, D. L., Jensen, M. D., \& Perry, S. E. (2005). Buku ajar keperawatan maternitas. Jakarta: EGC.

Fahmi. (2014). Hubungan antara dismenorea dengan usia menarche dan indeks massa tubuh. Medan: Universitas Sumatera Utara.

Isnaeni, Y., \& Kusmiati, E. (2016). Petunjuk praktikum keperawatan maternitas II. Yogyakarta: STIKes Surya Global.

Iswari, K. D. P., Surinati, I. D. A. K., \& Mastini, I. G. A. A. P. (2014). Hubungan dismenore dengan aktivitas belajar mahasiswi. COPING (Community of Publishing in Nursing), 2(3), 1-7.

Lestari, H., Metusala, J., \& Suryanto, D. Y. (2016). Gambaran dismenorea pada remaja putri sekolah menengah pertama di Manado. Sari Pediatri, 12(2), 99-102.

Mahmudiono, T. (2011). Fiber, PUFA and calcium intake is associated with the degree of primary dysmenorrhea in adolescent girl Surabaya, Indonesia. Journal Obstetrics $\mathcal{E}$ Gynecology.

Proverawati, A., \& Misaroh, S. (2009). Menarche. Yogyakarta: Nuha Medika.

Puji, A. I. (2009). Efektivitas senam dismenore dalam mengurangi dismenore pada remaja putri di SMUN 5 Semarang. Semarang: Universitas Diponegoro.

Marlinda, R., \& Purwaningsih, P. (2013). Pengaruh senam dismenore terhadap penurunan dismenore pada remaja putri di Desa Sidoharjo Kecamatan Pati. Jurnal Keperawatan Maternitas, 1(2), 118-123. 